\title{
Assessing the Quality of Quality Gate Reference Processes
}

\author{
Thomas Flohr \\ FG Software Engineering, Leibniz Universität Hannover Welfengarten 1, \\ 30167 Hannover, Germany \\ thomas.flohr@inf .uni-hannover.de
}

\begin{abstract}
Many software developing companies use Quality Gates to mitigate quality problems and to steer projects in time. The necessary structures, activities, methods, roles and documents can be encapsulated in a Quality Gate reference process, which then can be tailored to fulfill the needs of different projects. Each company has to implement a Quality Gate reference process individually because quality and business goals differ. In order to improve the quality of a Quality Gate reference process a company has to assess the quality of the implemented Quality Gate reference process. This paper presents a concept allowing the conduction of such an assessment by assessing the concepts of a Quality Gate reference process separately. The concepts (which have to be assessed) were identified by an empirical study involving several companies and by analyzing current literature. The assessment concept was validated by assessing the quality of different Quality Gate reference processes from literature.
\end{abstract}

Keywords: Quality Gates, Process Assessment, Continous Process Improvement.

\section{Introduction}

Quality Gates are significant milestones and decision points within a project [5]. At each Quality Gate certain project results are evaluated against predefined and quality focused criteria. Based on the fulfillment of these criteria gatekeepers (which are usually part of the quality management) make a decision whether a project may proceed or not. Consequently, the quality situation of a project can be uncovered to the management and actions can be made in time.

Quality Gates are often used in certain domains, e.g. in car development or in serial production of industrial goods [8. In the domain of software development Quality Gates are used cumulatively in the last years 9]. Unfortunately, a theoretical foundation for Quality Gates and for the assessment of the process quality of Quality Gate reference processes is currently missing in the domain of software development. Assessments are necessary in order to identify potential shortcomings within an implemented Quality Gate reference process. A negative assessment can used as a starting point of a continuous improvement process. A positive assessment can be used to attest a project's client the ability to control quality and to steer a project. 
A software company can use Quality Gates in two ways (we will refer to them as strategies):

- Quality Gates as a quality guideline: The same set of Quality Gates (and criteria) is applied to all projects resulting in a comparable and at least an equal minimum quality level in all these projects.

- Quality Gates as a flexible quality strategy: A suitable Quality Gate process is applied to each project to exactly meet the project's needs.

A Quality Gate reference process encapsulates special structures, activities, methods, roles and documents, which can be implemented by a software company individually in order to satisfy their quality and business needs. This Quality Gate reference process then can be tailored to meet the needs of a given project. The result is a Quality Gate process, containing a set of criteria and a set of Quality Gates. Moreover, the intensity of the gate review and other methods and activities are determined. In the final step the Quality Gate process is instantiated by assigning persons to the roles and by assigning a fixed date to each determined Quality Gate. A gate management (which is usually part of the quality management) can continuously improve the implemented Quality Gate reference process. To achieve this task, the gate management needs to know possible shortcomings: the assessment concept described in this paper can provide a strong assistance here. Figure 1 summarizes the different steps of tailoring and instantiation.

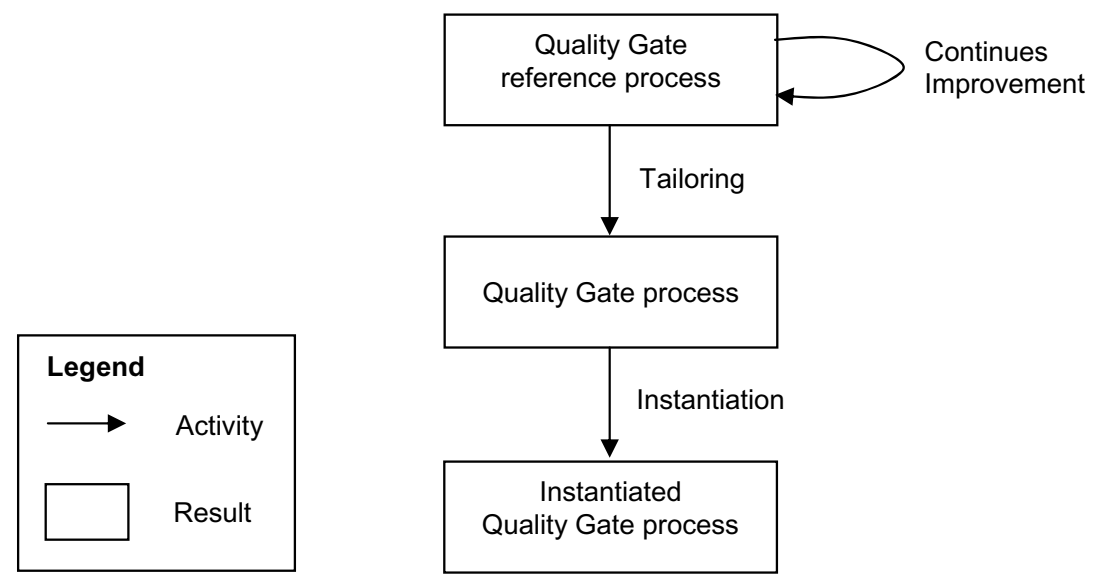

Fig. 1. Tailoring of a Quality Gate reference process

\section{$1.1 \quad$ Outline}

This paper is structured in four main sections. Section two shows the concepts a software company has to implement to gain a Quality Gate reference process. Section three presents our assessment concept as well as the possible impacts resulting from shortcomings in the implementation. Furthermore, it is described 
how the assessment concept can be used as a starting point for a continuous improvement process. Section four shows the application of the concept on different Quality Gate reference processes from literature. Finally, section five contains a conclusion and an outlook.

\section{Concepts of Quality Gate Reference Processes}

In order to assess the process quality of a Quality Gate reference process we need to identify its concepts first. The concepts were identified through a empirical survey conducted among software companies. The survey lasted three months and was conducted in 2007. Overall, 11 questionnaires were sent back and evaluated. Furthermore, Quality Gate reference processes from literature [37] and from the V-Model XT reference process 2] of the German federal administration were analyzed.

To keep track of the identified concepts, the concepts are structured in different categories. The categories and their concepts are described in detail in the following sections.

\subsection{Structural Concepts}

The structural category only contains one concept: the gate network. A Quality Gate reference process can have an arbitrary number of gate networks. Each gate network holds information on a set of Quality Gates and the order in which these Quality Gates have to be passed. Each gate network is usually assigned to a certain project type. Smaller projects tend to have very few or even no Quality Gates, because the resource overhead is too high. However, important or high-risk projects usually have to pass more (or a maximum number of) Quality Gates. In case a software company pursuits the strategy Quality Gates as a quality guideline the company's Quality Gate reference process only holds one gate network, which is applied to all projects. The strategy Quality Gates as a flexible quality strategy allows having more than one gate network. Figure 2 shows a classical waterfall process while figure 3 shows a gate network which can be applied to the waterfall process.

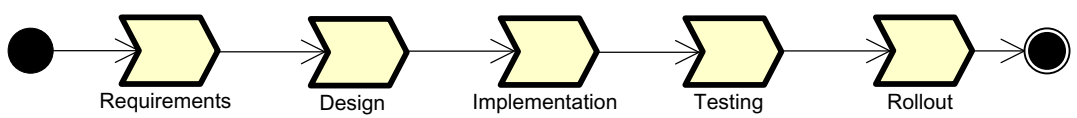

Fig. 2. A classical waterfall process

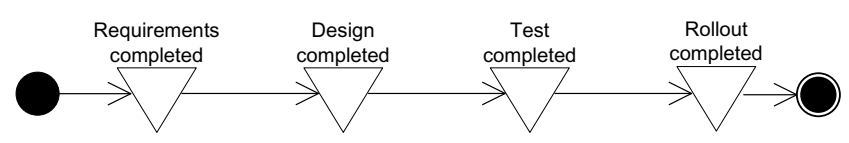

Fig. 3. A possible gate network for a waterfall process 


\subsection{Criteria Concepts}

Criteria concepts concern the creation of criteria. More precisely, criteria concepts concern how and when criteria are created and which roles are responsible for the process of creation. Table 1 summarizes the criteria concepts.

Table 1. Overview of the identified criteria concepts

\begin{tabular}{ll}
\hline Concept & Description \\
\hline Criteria Creation & $\begin{array}{l}\text { The criteria creation exactly defines, when in a project the cre- } \\
\text { ation of criteria takes place. The creation can take place at the } \\
\text { project's start, in the planning or conduction phase. Further- } \\
\text { more, (systematic) methods for criteria creation and the indi- } \\
\text { viduality of the criteria have to be defined. For example the } \\
\text { strategy Quality Gates as a quality guideline requires to fix the } \\
\text { criteria in a catalogue resulting in a low individuality of criteria. }\end{array}$ \\
\hline Criteria Creator & A software company must define which roles are responsible \\
& for the creation of criteria. If a software company pursuits the \\
& strategy Quality Gates as a quality guideline criteria are created \\
& by the process management and are continuously improved by \\
& a dedicated gate management. Depending on the abstractness \\
& of criteria the creation also requires to interpret criteria in a \\
& project's context to make them applicable. Usually, the inter- \\
& pretation is negotiated between the (internal) customers and \\
(internal) contractors of a project.
\end{tabular}

\subsection{Review Concepts}

Review concepts concern the systematic process of checking a project's results against predefined criteria. Table 2 summarizes the review concepts.

\subsection{Steering Concepts}

Steering concepts concern the decision making which have to be done as a part of the gate review. Table 3 summarizes the steering concepts.

\subsection{Tailoring Concepts}

Tailoring concepts concern the tailoring and continuous improvement of an implemented Quality Gate reference process (also compare to figure 1). Table 4 summarizes the tailoring concepts. 
Table 2. Overview of the identified review concepts

\begin{tabular}{|c|c|}
\hline Concept & Description \\
\hline Gate Review & $\begin{array}{l}\text { Within in the gate review a project's results are checked against } \\
\text { the criteria defined in the criteria creation. Similar to technical } \\
\text { reviews (e.g. inspections } 4 \text {. or peer reviews }[10] \text { ) different inten- } \\
\text { sities of gate reviews exist. Depending on the intensity a gate } \\
\text { review requires more or less resources, but varies in reliability } \\
\text { at the same time. }\end{array}$ \\
\hline Gate Moderator & $\begin{array}{l}\text { A gate moderator is responsible for a smooth and efficient con- } \\
\text { duction of the gate review. A software company has to map } \\
\text { a role to the role of a gate moderator, to ensure that all gate } \\
\text { reviews run smoothly. }\end{array}$ \\
\hline Reviewer & $\begin{array}{l}\text { The main task of a reviewer is to assess the quality of the project } \\
\text { results against the criteria. Ideally, each reviewer possesses the } \\
\text { necessary technical abilities to conduct the assessment without } \\
\text { problems. }\end{array}$ \\
\hline $\begin{array}{l}\text { Project Represe } \\
\text { tive }\end{array}$ & $\begin{array}{l}\text { A project representative answers questions and defends his } \\
\text { project within the gate review. A software company should as- } \\
\text { sign a project role here, to ensure that checking failures are } \\
\text { avoided (e.g. like a project's result has been overlooked). }\end{array}$ \\
\hline Protocol & $\begin{array}{l}\text { The protocol captures different results of a gate review. Major } \\
\text { results are: the decision, the degree of fulfillment of the criteria } \\
\text { and the actions having to be taken. A Quality Gate reference } \\
\text { process should define a template as a guideline for the protocol. }\end{array}$ \\
\hline Protocol Writer & $\begin{array}{l}\text { The protocol writer captures the protocol of a gate review. A } \\
\text { software company should assign a role here, to ensure that the } \\
\text { protocol is captured consistently. }\end{array}$ \\
\hline
\end{tabular}

\section{The Assessment Concept}

The main idea of our assessment concept is very close to the idea of process capability maturity models such as SPICE [6] and CMMI [1]: it does not matter how a software company implements a Quality Gate concept because the actual implementation depends on the company's size and its domain. Rather it is only relevant to rate the degree of implementation of a concept. Nonetheless, a faulty implementation of a concept can cause problems even if the concept is fully implemented.

Our assessment concept differs in two ways from the well-known process capability maturity models:

- SPICE and CMMI do not directly advocate the usage of Quality Gates in order to evaluate a project's results. Rather quality checks might be performed by other activities too. Therefore SPICE and CMMI are not a proper starting point to assess Quality Gate reference processes in detail. 
Table 3. Overview of the identified steering concepts

\begin{tabular}{ll}
\hline Concept & Description \\
\hline Decisions & A software company has to define the actions which can be taken \\
& in a Quality Gate. Possible decisions are arbitrary combinations \\
& of the following decisions: go, conditional-go, repeat-gate, hold \\
& and kill. The allowed decisions are a subset of these decisions.
\end{tabular}

Gatekeeper

Gatekeepers are decision makers. A software company has to set a profile for a gatekeeper. Usually gatekeepers have a technical or quality management background. Nonetheless, if business criteria are checked within a quality gate the profile of a gatekeeper has to be defined accordingly. Additionally, it has to be defined which types of gatekeepers can make which types of decision.

Decision Support

Decision support concerns methods to map the degree of fulfillment and the importance of criteria to a decision. Decision support can be implemented either systematically or intuitively.

- Our assessment concept does not include certain maturity levels a software company can develop in. Each can concept can be improved individually. Nonetheless, it is possible the concepts in one category.

Based on this idea all concepts can be assessed on a three-valued ordinal scale. The following listing explains the values of the scale.

- A • denotes a fully implemented concept. This means that it is clear, how the concept has to be mapped to a project in order to be applicable. A fully implemented concept must be fixed within a process description. For example a role with a clear and fixed ability profile is a fully implemented concept.

- A $\star$ denotes a partly implemented concept. A partly implemented concept must be interpreted in order to be applicable. Partly implemented concepts often are fixed as an abstract description or a written description is missing, but is intuitively clear how the concept has to be applied. Sometimes it is necessary to leave a concept abstract because it must be applied to different business units of the software company. For example the protocol concept is partly implemented if most people in a company know how to write the protocol but no fixed template exists.

- A o denotes an unimplemented concept. Unimplemented concepts do not provide any hints how to apply the concept. Reasons could be:

- The process management forgot to implement the concept.

- The concept was left unimplemented, because the Quality Gate reference process must be used in different business units in the company and each business unit has to implement it individually.

- The concept was intentionally left unimplemented, because the process management regards it as unimportant. 
Table 4. Overview of the identified tailoring concepts

\begin{tabular}{ll}
\hline Concept & Description \\
\hline Gate Management & $\begin{array}{l}\text { The gate management is responsible for the continuous im- } \\
\text { provement of an implemented Quality Gate reference process. } \\
\text { Depending on the size of a company the gate management } \\
\text { can be implemented in various intensities ranging from non- } \\
\text { implemented to a dedicated gate management. }\end{array}$ \\
\hline Process Tailorer & $\begin{array}{l}\text { A process tailorer's task is to tailor a suitable Quality Gate } \\
\text { process (also compare to figure 1). A software company has to } \\
\text { assign a role who is responsible for tailoring. }\end{array}$ \\
\hline Tailoring Method & $\begin{array}{l}\text { A tailoring method maps a project situation and the tailorable } \\
\text { elements to suitable Quality Gate process. A tailoring method } \\
\text { can either be systematic or intuitive. }\end{array}$ \\
\hline Plements & $\begin{array}{l}\text { Tailorable elements concern the aspects of a Quality Gate ref- } \\
\text { erence process which can be tailored to better match a given } \\
\text { project situation. For example, if the gate network is a tailorable } \\
\text { concept the Quality Gate reference process has to provide vari- } \\
\text { ous gate networks. }\end{array}$ \\
\hline $\begin{array}{l}\text { A project model helps to formally describe various project situ- } \\
\text { ations. A project model contains a set of attributes (e. g. project } \\
\text { size, domain and risk) and for each attribute a set of values. A } \\
\text { project situation assigns a value to each attribute. In this way } \\
\text { a project can be formally described. In order to effectively and } \\
\text { repeatable tailor a Quality Gate reference process, a software } \\
\text { company has to design a project model. }\end{array}$ \\
\hline
\end{tabular}

\subsection{Impacts of Shortcomings}

Depending on the degree of implementation of a certain concept different impacts might exist. Table 5 shows an overview of possible impacts caused by shortcomings in the implementation of the concepts.

\subsection{Continues Improvement}

An assessment can be used as a starting point of a continuous improvement process. A continuous improvement process includes the following steps (which ideally have to be repeated in cyclic order):

1. Either the process management or the dedicated gate management (or at best external assessors) conduct an assessment of the software company's Quality Gate reference process.

2. Based on the shortcomings possible impacts are identified (compare to table 5). The identified impacts are check against existing problems resulting in a set of concepts which have to be improved. 
Table 5. Overview of possible impacts

\begin{tabular}{|c|c|c|}
\hline Shortcoming & Description & Impacts \\
\hline $\begin{array}{l}\text { Undefined Gate Net- } \\
\text { work }\end{array}$ & $\begin{array}{l}\text { The set of Quality } \\
\text { Gates or the order of } \\
\text { Quality Gates is un- } \\
\text { clear. }\end{array}$ & $\begin{array}{l}\text { Different Gate Networks might } \\
\text { be used. Comparability be- } \\
\text { tween projects and quality } \\
\text { level might be lower. }\end{array}$ \\
\hline Undefined Role & $\begin{array}{l}\text { Unqualified persons } \\
\text { could be assigned to } \\
\text { a role or a role stays } \\
\text { unallocated. }\end{array}$ & $\begin{array}{l}\text { Depending on the role project } \\
\text { results might be checked in- } \\
\text { adequately, wrong decisions } \\
\text { are made, inadequate criteria } \\
\text { might be created, the protocol } \\
\text { is inadequate or activities (es- } \\
\text { pecially the gate review) be- } \\
\text { come tenacious. }\end{array}$ \\
\hline Undefined Activities & $\begin{array}{l}\text { The gate review or } \\
\text { the criteria definition } \\
\text { might be unclear. }\end{array}$ & $\begin{array}{l}\text { Inadequate criteria might be } \\
\text { created or project results are } \\
\text { checked inadequately. }\end{array}$ \\
\hline Undefined Protocol & $\begin{array}{l}\text { The contents of the } \\
\text { protocol is unclear. }\end{array}$ & $\begin{array}{l}\text { Decisions, criteria assessment } \\
\text { or actions might be untrace- } \\
\text { able in the future. }\end{array}$ \\
\hline $\begin{array}{ll}\text { Undefined } & \text { Tailoring } \\
\text { and Gate } & \text { Manage- } \\
\text { ment } & \end{array}$ & $\begin{array}{l}\text { It is unclear which con- } \\
\text { cepts can be tailored } \\
\text { in order to obtain a } \\
\text { suitable Quality Gate } \\
\text { process. A gate man- } \\
\text { agement is not imple- } \\
\text { mented. }\end{array}$ & $\begin{array}{l}\text { Inadequate Quality Gate pro- } \\
\text { cesses might be applied to } \\
\text { projects. Quality Gate pro- } \\
\text { cesses might be used inconsis- } \\
\text { tently despite similar projects. } \\
\text { The Quality Gate reference } \\
\text { process is not continuously im- } \\
\text { proved. }\end{array}$ \\
\hline $\begin{array}{l}\text { Undefined Type of } \\
\text { Criteria }\end{array}$ & $\begin{array}{l}\text { Different types of crite- } \\
\text { ria might be applied to } \\
\text { (similar) projects. }\end{array}$ & $\begin{array}{l}\text { Non-quality related criteria } \\
\text { might be checked excessively } \\
\text { or non-quality related crite- } \\
\text { ria are not checked (despite } \\
\text { it is necessary in a given } \\
\text { project). Project results might } \\
\text { be checked against inconsis- } \\
\text { tent criteria. }\end{array}$ \\
\hline $\begin{array}{l}\text { Undefined Decisions } \\
\text { and Decision support }\end{array}$ & $\begin{array}{l}\text { It is unclear which de- } \\
\text { cisions can be made } \\
\text { within a Quality Gate } \\
\text { and who is allowed to } \\
\text { make certain decisions. } \\
\text { Systematic methods to } \\
\text { receive repeatable deci- } \\
\text { sions beyond the scope } \\
\text { of a project are not im- } \\
\text { plemented. }\end{array}$ & $\begin{array}{l}\text { Decisions are made inconsis- } \\
\text { tently. Possible decisions are } \\
\text { not made while impossible de- } \\
\text { cisions might be taken. }\end{array}$ \\
\hline
\end{tabular}


3. The concepts which were identified in the last step are set as improvement goals. After the goals are achieved proceed with step 1.

It is possible to improve the implementation of a concept by one level in each improvement cycle. For example if a role is completely unimplemented, we could first implement an abstract role profile in the first cycle (leading to a partly implemented concept) and then (after enough experience was gathered) refine and fix the role profile in the second (or later) cycle.

\section{Practical Application of the Assessment Concept}

Our assessment concept was applied to different Quality Gate reference processes from literature. Table $[$ summarizes the results of the assessment of these Quality Gate reference processes.

The assessment shows different problems. Despite Pfeifer's Quality Gate reference process pursuits the strategy Quality Gates as a flexible quality strategy no tailoring concepts are implemented leading to different possible impacts (see table 5, row Undefined Tailoring and Gate Management).

The Quality Gate reference process of the V-Model XT leaves the criteria concept and the decision support concept unimplemented. Furthermore, no gate management is implemented. Consequently, project results might be checked against different criteria and project results might be judged inconsistently from project to project.

Table 6. The assessment concept applied to Quality Gate reference processes

\begin{tabular}{llccc}
\hline Category & Concept & Pfeifer [7] & V-Model XT [2] & Stage-Gate [3] \\
\hline Structural Concepts & Gate Network & $\bullet$ & $\bullet$ & $\bullet$ \\
\hline \multirow{5}{*}{ Criteria Concepts } & Criteria Creation & $\bullet$ & $\star$ & $\star$ \\
& Criteria Creator & $\bullet$ & $\bullet$ & $\star$ \\
& Criteria & $\star$ & $\circ$ & $\bullet$ \\
\hline \multirow{5}{*}{ Review Concepts } & Gate Review & $\star$ & $\bullet$ & $\star$ \\
& Gate Moderator & $\circ$ & $\bullet$ & $\star$ \\
& Reviewer & $\bullet$ & $\bullet$ & $\star$ \\
& Project Represent. & $\star$ & $\bullet$ & $\bullet$ \\
& Protocol & $\star$ & $\bullet$ & $\bullet$ \\
\hline \multirow{5}{*}{ Steering Concepts } & Protocol Writer & $\circ$ & $\bullet$ & $\bullet$ \\
& Decision & $\bullet$ & $\bullet$ & $\star$ \\
\hline \multirow{5}{*}{ Tailoring Concepts } & Decision Support & $\star$ & $\bullet$ & $\star$ \\
& Gate Management & $\circ$ & $\bullet$ & $\bullet$ \\
& Tailoring Method & $\circ$ & $\bullet$ & $\bullet$ \\
\hline & Pailorable Elements & $\circ$ & $\bullet$ & $\bullet$ \\
\hline
\end{tabular}


The Quality Gate reference process of Cooper's Stage-Gate concept leaves two concepts unimplemented: process tailorer and protocol writer. Therefore, it is unclear who is responsible for the tailoring. Decisions and actions might be untraceable, because a proper protocol might be uncreated.

\section{Conclusion and Outlook}

In this paper a concept to assess the process quality of a Quality Gate reference processes was presented. In order to successfully establish Quality Gates a software company has to implemented certain concepts. These concepts were identified by conducting an empirical study involving several software companies and by analyzing literature.

Depending on which concepts have been left unimplemented certain impacts are possible. An assessment makes this impacts visible for the process management. The assessment is then a starting point for a continuous improvement process. Furthermore, it can be used to show clients that Quality Gates are properly implemented (in case the assessment was positive).

The assessment concept was applied to different Quality Gate reference processes from literature. Thus several possible impacts could be identified.

Our assessment concept was not applied to real Quality Gate reference processes implemented in companies so far. Applications of our assessment concept in software companies is necessary and planned. These applications could possibly lead to a refined assessment scale and to the identification of more concepts.

\section{References}

1. CMMI for Development Version 1.2. Carnegie Mellon Software Engineering Institute, SEI (2006)

2. V-Modell, X.T. (Version 1.2). Koordinierungs- und Beratungsstelle der Bundesregierung für Informationstechnik in der Bundesverwaltung (2006)

3. Cooper, R.G.: Winning At New Products: Accelerating the Process from Idea to Launch. Perseus Books Group, Cambridge (2001)

4. Fagan, M.E.: Design and Code Inspections to Reduce Errors in Program Development. IBM Systems Journal 15, 258-287 (1976)

5. Hawlitzky, N.: Integriertes Qualitätscontrolling von Unternehmensprozessen Gestaltung eines Quality Gate-Konzeptes. TCW Wissenschaft und Praxis. TCW Transfer-Centrum (2002)

6. Hörmann, K., Dittmann, L., Hindel, B., Müller, M.: SPICE in der Praxis. In: Interpretationshilfe für Anwender und Assessoren. dpunkt Verlag (2006)

7. Pfeifer, T., Schmidt, R.: Das Quality-Gate-Konzept: Entwicklungsprojekte softwareintensiver Systeme verlässlich planen. Industrie Management 19(5), 21-24 (2003)

8. Scharer, M.: Quality Gate-Ansatz mit integriertem Risikomanagement. PhD thesis, Institut für Werkzeugmaschinen und Betriebstechnik der Universität Karlsruhe (2001) 
9. Schubert, P., Guiver, T., MacDonald, R., Yu, F.: Using Quality Measures to Manage Statistical Risks in Business Surveys. In: European Conference on Quality in Survey Statistics (2006)

10. Wiegers, K.E.: Peer Reviews in Software: A Practical Guide. Addison-Wesley Information Technology Series (2002) 